\title{
What Psychology Can Contribute to Contemporary Teacher Education: Basic Concepts and Exemplary Implementations
}

\author{
Stephan Dutke, Manfred Holodynski, Elmar Souvignier
}

\begin{abstract}
We describe basic concepts of contemporary teacher education from a psychological perspective, typified by examples from teacher education programs run at the University of Münster, Germany. After describing the context of teacher education in Germany, the criteria are discussed which determine the selection of psychological contents to be included into teacher education curricula. Furthermore, three curriculum components are discussed that help to adopt a psychological perspective on instruction at school. Classroom videos reduce the distance between psychological knowledge suitable to guide teacher behaviour on the one hand and examples of how teachers actually behave during class on the other. Students' small-scale classroom research projects bridge the gap between theory and practice, and curriculum components focusing on individual differences help to raise awareness for diagnostics, individual aid, and inclusion. Finally, psychology's role in teacher education is discussed with regard to relevant content knowledge and methodological knowledge teacher education curricula might benefit from.
\end{abstract}

Keywords: teacher education; video-based instruction; evidence-based teaching; research-based learning.

Current educational psychology is concerned with the process of education with regard to all persons, roles, and institutions involved in this process including, for example, children, parents, families, schools, and higher education institutions. In its beginnings, however, educational psychology was almost entirely concerned with the design of instruction at school (cf. Schönpflug, 2004). Consequently, early publications in educational psychology were often monographs summarizing psychological knowledge for teachers (e.g.,
Herget, 1914). Some of these books, originally written for teachers, even enriched psychology itself - Thorndike's Educational Psychology (1913) is an impressive example. Since then, educating teachers has been an important field of application for psychological research. Psychology's impact on teacher education today, however, is not only a function of fruitful research and the availability of relevant psychological knowledge but also a matter of societal, political, and legal conditions. In this challenging context, psychology 
seeks strategies of appropriately selecting psychological knowledge for teacher education programs and teaching psychology in these programs.

\section{Context: Psychology's}

\section{SHARE IN TEACHER EDUCATION IN GERMANY}

Contemporary teacher education in Germany is a complex system. Germany is a federal republic comprising 16 states, each with its own parliament, legislation, and government. Educational issues, from the basic to the tertiary level, including teacher education, lie within the authority of each of these states. Therefore, we will describe some of the commonalities of these sixteen systems, while some features characterizing the educational systems of specific states within the Federal Republic of Germany will be neglected.

Today, teachers are educated in a threephase system: Bachelor's (3 years) and Master's phase (2 years) at the university, and an 18-month traineeship at school. At the university, students study three subjects: the two school subjects they intend to teach at school including subjectspecific didactics, and the third subject, educational sciences, which comprises contributions from pedagogy, psychology, and sociology. During their school-based traineeships, students teach under the supervision of experienced teachers, and they teach independently in part. At the end of their traineeship, they pass practical and theoretical examinations under the superintendence of the school authorities.

Although, de jure, the German states act independently with regard to their educational systems, the Ministers of Education and Cultural Affairs cooperate in a standing conference. This conference have agreed upon a set of national standards that each Bachelor's and Master's program for prospective teachers must satisfy. The standards for educational sciences, for example (Kultusministerkonferenz, 2014), postulate that students acquire 11 competences (e.g., the competence to plan instruction taking individual differences into account, or the competence to support the development of self-regulated learning and working). The standards also present adequate methods and thematic foci that might foster establishing these competences. However, the standards do not relate to the academic disciplines assembled under the umbrella construct of educational sciences. To what extent pedagogy, psychology or sociology contribute to establishing the various competences is the responsibility of the respective universities though. The division of labour is due to the teaching capacities and powers of the academic disciplines within educational sciences and their cooperative procedures within the university. Consequently, although psychological research is able to contribute to the majority of competences, methods, and foci mentioned in the national standards, psychology's actual involvement in teacher education programs depends on their interests, teaching capacity, and standing within a given university. 
In this "free play of forces", psychology's share in teacher education programs varies enormously across universities. The University of Münster, for example, is one of the larger German universities with ca. 43,800 students (Westfälische Wilhelms-Universität, 2017) including $22 \%$ teacher students. Psychology dedicates four full professorships (developmental, general, social psychology, and diagnostics and evaluation) completely to the teacher education programs. In total, the Institute for Psychology in Education invests ca. 100 teaching hours per semester into teacher education. In the Bachelor's phase, psychology is offered as an obligatory module of 7 credit points ${ }^{1}$ on learning, development, social processes, and diagnostics. In the Master's phase, psychology is offered in form of an optional module on learning, development, and social processes (7 credit points), and an advanced optional module focusing on research and application topics relevant to learning, teaching, diagnostics, and intervention in the classroom context (6-10 credit points depending on the school form). Additionally, psychology offers ca. 12 of 33 courses in which students are supervised during their 6-month school internship in the Master's phase as well as preparation courses in research methods for about one third of the Master's students in all teacher education programs at the University of Münster.

\section{What to Teach: Selecting PSYCHOLOGICAL CONTENTS FOR TEACHER EDUCATION PROGRAMS}

In recent decades, psychological research productivity has increased dramatically. An extensive amount of information has been accumulated that is related to processes in schools at the individual level (e.g., learning, motivation or self-regulation of students and teachers), at the social level (e.g., teaching, educating, and leading students), and at the organizational level (leadership in schools, organizational development, and change management). Therefore, a prevalent question is how to select psychological contents for teacher education curricula - considering that the portion of the study program that can be spent on psychological topics is limited. ${ }^{2}$

The most general criterion for selecting psychological contents refers to the national standards for educational sciences in teacher education (Kultusministerkonferenz, 2014). Primarily, psychological knowledge related to these standards should be considered for being included into the curriculum. For example, the

\footnotetext{
${ }^{1}$ One credit point corresponds to a workload of 25-30 hours for the students. The total amount of credit points for educational sciences in the Bachelor's phase ranges from 20 to 44 credit points and in the Master's phase from 20 to 39 points depending on the school form.

2 Thanks are due to the members of the EFPA Board of Educational Affairs (http://educational-affairs.efpa. $\mathrm{eu} /$ ). The Board intensively discussed criteria for the development of psychology curricula for non-psychology students, which were adopted for this passage (see Dutke et al., 2018).
} 
standards require teachers to participate in projects of school development (Standard No. 11). Therefore, knowledge about change management processes in organizations should be considered a curriculum component. In contrast, none of the standards requires teachers to intervene independently in cases of severe test anxiety. For this reason, developing or applying interventions focusing on test anxiety are not considered despite being closely related to school problems.

In the next step, psychological content that satisfies the first criterion needs to be evaluated with regard to the empirical evidence it is based on. Psychological research has generated theoretically well-founded and empirically investigated principles of learning and teaching, for example, spaced learning, collaborative learning, practice testing, and many others. Basic principles of effective teaching and learning have recently been summarized in several publications (e.g., Cranney, 2013; Dunlosky et al., 2013; Dunn et al., 2013; Graesser, Halpern, \& Hakel, 2008; Roediger \& Pyc, 2012; Schwartz \& Gurung, 2012). The basic idea is that teaching and learning at school can be improved when teachers consider the psychological evidence in designing learning opportunities and learning conditions. However, constructs lacking a solid empirical basis also have been recommended to teachers. The idea of learning types (individuals learn better when they receive information in the modality they prefer) is one of these prominent misconceptions about human cognition (Pashler et al., 2008). Several other publications also identified prominent concepts based on theoretical misconceptions or that lack empirical evidence (e.g., Dekker et al., 2012; Kirschner \& De Bruyckere, 2017; Kirschner \& van Merrienboer, 2013). Thus, the second criterion for selecting psychological contents for teacher education curricula is the degree of theoretical consistency and empirical evidence. Dunn et al. (2013) and others coined the term "evidence-based teaching" for this approach.

At the most specific level, selection criteria are applied that are expected to enhance curriculum acceptance. A key aspect is the transfer of psychological knowledge to the work processes executed by teachers. For example, the role of attributional processes in the development of achievement motivation satisfies the first criterion. The national standards for teacher education require teachers to know about the modification of motivational processes (Standard No. 2). This topic also satisfies the second criterion. How attributional processes modify achievement motivation is thoroughly investigated and key results have been replicated (e.g., Reisenzein, 2014). Nevertheless, a gap remains between the psychological content and the work processes to which this content should be applied. Unless students understand how attributional processes can be addressed, for example, in giving feedback on student performance, in reacting to student statements during a lesson or generally in classroom management, acceptance and learning success might be low. Therefore, preferably psychological content should 
be included in the curriculum for which this translation process can be scaffolded effectively.

\section{HOW TO TEACH PSYCHOLOGY IN TEACHER EDUCATION PROGRAMS}

In the following part, we describe three core elements of our curricula that have been developed during the last decade.

\section{Video-based teaching}

One challenge of teacher education is how to introduce practice into the lectures and seminars at a university level. Using classroom videos is an extraordinary possibility to bridge the gap between propositional knowledge and case-based as well as strategic knowledge. Whereas the former is represented in educational and psychological theories, both latter types of knowledge are necessary in order to notice and analyse teaching and learning processes in classrooms as well as to act appropriately. Classroom videos carry the complexity, simultaneity, immediacy, and unpredictability of real classroom situations and, therefore, have been evaluated as suitable tools in educating prospective teachers (e.g., Roth et al., 2011; Santagata \& Yeh, 2014). Stopping the video and repeating the observation enables students to analyse an event in detail and from several perspectives. Different facets of learning and teaching can be focused on (e.g., classroom management and instructional quality) and analysed from different perspectives (e.g., of students, teachers or independent observers, cf. Goldman et al., 2007).

In our teacher education programs, classroom videos are used increasingly for these purposes. Lecturers use them to illustrate empirically validated strategies of effective teaching and to train future teachers in their professional vision of relevant teaching and learning events in classrooms as a prerequisite for effective teaching (Hellermann, Gold, \& Holodynski, 2015). Sherin (2007) introduced the concept of professional vision and defined it as a teacher's ability to notice relevant classroom interactions for teaching and learning and to interpret them on the basis of scientific theories and reasoning. Professional vision is seen as an indicator of situated and integrated teacher knowledge (Seidel \& Stürmer, 2014). Novices need to build elaborated knowledge structures about effective teaching and learning in order to focus on and interpret critical classroom situations appropriately.

At our institute, the concept of professional vision has been applied to the topic of classroom management. Classroom management is evidently important for the academic, social-emotional, and motivational development of students (Hattie, 2009) as well as for the health of teachers (Lauth-Lebens \& Lauth, 2016). The challenge of classroom management is not only monitoring disruptive student behaviour or managing transitions, but also maintaining the group focus on a class without neglecting the particular focus on individual students (Kounin, 1970). We constructed and validated a standard- 
ized test for assessing professional vision of classroom management (Gold \& Holodynski, 2017) and have used it to evaluate the advantages of using classroom videos for the training of this competence (Hellermann et al., 2015). Studies revealed that professional vision of classroom management increases substantially from Bachelor through Master pre-service teachers to expert in-service teachers (Gold \& Holodynski, 2017).

Our video-based seminars each consisted of 14 weekly meetings amounting to a total of 28 hours of intervention time plus homework during a 3-month period. All seminars consisted of two blocks. Block 1 aimed at building conceptual knowledge about classroom management and at introducing observation schemes for describing and interpreting classroom management events. It included an introductory lesson and six course lessons (14 hours) plus homework. Four lessons included (a) a theory-based introduction to classroom management focused on monitoring (e.g., withitness), managing momentum (e.g., a smooth transition between activities), and establishing rules and routines, (b) an explanation and demonstration of these three facets of classroom management with short video clips, and (c) a guided theory-based analysis of elementary classroom teaching in which student teachers observed and interpreted classroom management related events presented in the video clips. In Block 2, students analysed a complete 90-minute classroom lesson. Students worked in teams of four members each. Each team developed a lesson plan for teaching (90 min) and each member instructed for a 20-minute part of the whole lesson in the class. Each lesson was videotaped. Then pairs in each team first analysed their own teaching and then the teaching of their team members. Secondly, each team compared and discussed their analyses and prepared an oral presentation addressing two successful classroom management events and one improvable event. Each presentation was discussed in a plenary session with all students in the seminar.

We also explored an option of this type of seminar in which students did not analyse their own teaching but the teaching of others only. A quasi-experimental comparison, however, revealed that this type of seminar was less effective than the seminars in which students analysed their own and others' teaching (Gold, Hellermann, \& Holodynski, submitted).

To promote the usage of classroom videos in teacher education, we installed a video platform that consists of German classroom videos especially from early science education in primary schools (www.unimuenster.de/koviu), but also from other subjects (www.uni-muenster.de/ProVision). Additional materials (e.g., lesson plans, transcripts, and teaching materials) are provided to contextualize the documented videos and make them applicable for usage in diverse courses of teacher education.

\section{Small-scale classroom research projects}

Another challenge is helping students to establish a professional attitude in line 
with the scientist-practitioner model (Horn et al., 2007). Such an attitude includes the motivation and skills of applying theoretical knowledge to authentic professional situations and evaluating the effects of this application with scientific methods. We try to bridge this gap between theory and practice by instructing students to conduct small-scale classroom research projects during their six-month school internships in the Master's phase. At the core of these courses, we guide students to develop miniaturised research questions with respect to psychological concepts, which can be analysed from the perspective of research-based learning (Healey, 2005). Such questions can, for example, deal with teachers' feedback, student motivation, assessment, classroom management, and many other psychological concepts. To analyse concepts like these, research methods such as observation, survey, and tests are used. Whereas the didactical concept of research-based learning is a common framework in psychology, it can add a new perspective to teacher education: using empirical methods and meaningful research designs to reflect on theoretical concepts is a concrete step on the way to what Schön (1983) called a 'reflective practitioner'. Teaching basic issues of research methods and especially guiding students to develop feasible questions and convert them into concrete viable research designs contributes to such a systematic reflection of theory in school practice. For this reason, psychological courses preparing students for these school internships include basic empirical methods on the one hand, and the development of a research question based on psychological content on the other. Thus prepared, students move into schools, check if the planned designs need revisions, and systematically bridge theory to practice. They execute their projects and summarize theoretical background, research questions, designs, results, and reflections in short reports. Conducting these small-scale classroom research projects is a meaningful opportunity to guide students towards making theoretically well-founded and evidence-based reflections of classroom practice.

\section{Curriculum components focussing on individual differences}

Within the larger framework of a nationwide program to strengthen teacher education (Bundesministerium für Bildung und Forschung, 2016), the University of Münster decided to focus on developing teacher competences in dealing with the increasing heterogeneity of their students at school. In most German universities, teacher education is structured more or less independently by different faculties (e.g., science, education, languages, and social sciences). To overcome this situation, it was decided to build a common curriculum around one central topic. Considering the fact that topics like individualized instruction and inclusion have been implemented into education acts in all German states, it seemed useful to focus on 'dealing with diversity'. Therefore a program was set up to raise awareness of individual differences 
in the classroom and to increase knowledge on diagnostic procedures and interventions suitable to foster individual development. In this context, we focus on psychological attributes with a wide range of inter- and intra-individual variations, for example, metacognitive processes (e.g., Schöll \& Dutke, 2018). As a key didactical element of these courses, inter-individual variation is demonstrated by revealing the differences among the participants of a university seminar. Dealing with heterogeneity is a ubiquitous challenge and not a distant construct. Dealing with this challenge in a professional way, however, requires (a) theoretical knowledge about the psychological attribute focused on, (b) approaches to assessment, (c) attempts for intervention, and (d) the skills to evaluate individual progress. These four steps, which are prototypical of a psychological perspective within the context of (individualized) intervention, form a structure that can be transferred to other academic subjects. As outlined above, courses like these are embedded in a transdisciplinary curriculum, which implies the opportunity to share modules across academic disciplines and to collaborate with colleagues from other academic disciplines.

\section{Conclusion}

Asking what an academic discipline can contribute to teacher education at first refers to this discipline's body of knowledge and the question to what extent this knowledge might help teachers to cope with the everyday challenges of their profession. Psychological knowledge has grown rapid- ly, and since the very beginning of psychology's development as a discrete academic discipline, this knowledge has been applied to school-relevant domains: learning and memory, problem-solving and reasoning, and motivation and emotion represent some of the most prominent fields of application. The diversity and abundance of psychological knowledge potentially relevant to teachers call for well-founded criteria in selecting psychological contents for teacher education curricula. We hypothesize that psychology curricula are more useful when psychological contents are selected according to the extent of their theoretical consistency and empirical evidence, and we expect psychology curricula to be the more accepted in this context the more profoundly the selection of psychological contents is oriented towards the actual work processes of teachers.

Psychology, however, does not only provide applicable knowledge. The examples we presented demonstrate how psychological theories on learning and teaching, for example, not only contribute to improving teaching at school, but also to improving teacher education itself. The reason is that not only psychological content knowledge but also fundamental methodological ideas inherent to psychology can be transferred to teacher education. For example, considering the empirical evidence of hypotheses and theories is a basic procedure to maintain orientation within the field of psychological research and, at the same time, it is the core of the concept of evidence-based teaching. Accordingly, research-based learning is an important approach in learning 
and teaching psychology but it is on the way to become a paradigm for educating teachers as well. The idea of a scientifically reflective practitioner is a well-established model for professionals in psychology, but it could also be a model for teachers who become increasingly aware of the scientific basis of their professional behaviour. Video-based learning has its roots in numerous methods trying to connect psychological theory and authentic application situations systematically. Problem-based learning (e.g., Wiggins et al., 2016) or learning with the help of worked examples (Renkl, 2014) show many parallels to video-based teaching. Conceptualizing intra- and interindividual differences in human behaviour is one of the methodological core problems of psychological research. At the same time, it can provide orientation for teachers dealing with diversity among their students. In summary, our examples demonstrate that psychology not only provides useful content knowledge for prospective teachers, but can also inspire teacher education through its methodological approaches.

\section{RefERENCES}

Bundesministerium für Bildung und Forschung (2016). Neue Wege in der Lehrerbildung. Die Qualitätsoffensive Lehrerbildung [New ways of teacher education. The teacher education initiative]. Berlin: BMBF.

Cranney, J. (2013). Toward psychological literacy: A snapshot of evidence-based learning and teaching. Australian Journal of Psychology, 65, 1-4.

Dekker, S., Lee, N. C., Howard-Jones, P., \& Jolles, J. (2012). Neuromyths in education: Prevalence and predictors of misconceptions among teachers. Frontiers of Psychology, 3.

Dunlosky, J., Rawson, K. A., Marsh, E. J., Nathan, M. J., \& Willingham, D. T. (2013). Improving students' learning with effective learning techniques: Promising directions from cognitive and educational psychology. Psychological Science in the Public Interest, 14, 4-58.

Dunn, D. S., Saville, B. K., Baker, S. C., \& Marek, P. (2013). Evidence-based teaching: Tools and techniques that promote learning in the psychology classroom. Australian Journal of Psychology, 65, 5-13.

Dutke, S., Bakker, H., Sokolová, L., Stuchlikova, I., Salvatore, S., \& Papageorgi, I. (2018). Psychology curricula for non-psychologists? A framework recommended by the EFPA Board of Educational Affairs. Psychology Learning and Teaching.

Gold, B., \& Holodynski, M. (2017). Using digital video to measure the professional vision of elementary classroom management: Test validation and methodological challenges. Computers \& Education, 107, 13-30.

Gold, B., Hellermann, C., \& Holodynski, M. (submitted). Video-based learning in teacher education for promoting professional vision of classroom management - the role of different analytic perspectives.

Goldman, R., Pea, R., Barron, B., \& Derry, S. J. (Eds.). (2007). Video research in the learning sciences. Mahwah, NJ: Routledge. 
Graesser, A. C., Halpern, D. F., \& Hakel, M. (2008). 25 principles of learning. Washington, DC: Task Force on Lifelong Learning at Work and at Home.

Hattie, J. (2009). Visible learning: A synthesis of over 800 meta-analyses relating to achievement. New York: Routledge.

Healey, M. (2005) Linking research and teaching exploring disciplinary spaces and the role of inquiry-based learning. In R. Barnett (Ed.), Reshaping the university: New relationships between research, scholarship and teaching (pp. 67-78). Maidenhead, UK: McGraw-Hill.

Hellermann, C., Gold, B., \& Holodynski, M. (2015). Förderung von Klassenführungsfähigkeiten im Lehramtsstudium [Promoting classroom management skills in teacher education]. Zeitschrift für Entwicklungspsychologie und Pädagogische Psychologie, 47, 97-109.

Herget, A. (1914). Psychologie und Erziehungslehre [Psychology and Education]. Prague: Haase. Horn, R. A., Troyer, J. A., Hall, E. J., Mellott, R. N., Cotè, L. S., \& Marquis, J. D. (2007). The scientist-practitioner model: A rose by any other name is still a rose. American Behavioral Scientist, 50, 808-819.

Kirschner, P. A., \& De Bruyckere, P. (2017). The myths of the digital native and the multitasker. Teaching and Teacher Education, 67, 135-142.

Kirschner, P. A., \& van Merrienboer J. J. G. (2013). Do learners really know best? Urban legends in education. Educational Psychologist, 48, 169-183.

Kounin, J. S. (1970). Discipline and group management in classrooms. New York: Holt, Rinehart and Winston.

Kultusministerkonferenz. (2014). Standards für die Lehrerbildung: Bildungswissenschaften: Beschluss der Kultusministerkonferenz vom 12.0 6. 2014 [Standards for teacher education. Educational sciences: Resolution of the Standing Conference of the Ministers for Cultural Affairs and Education from June 12, 2014]. Retrieved under https://www.kmk.org

Lauth-Lebens, M., \& Lauth, G. W. (2016). Behavioural modification and classroom management skills as protective factors against mental health problems in teachers: A synthesis of research. Journal of Mental Disorders and Treatment, 2, 107.

Pashler, H., McDaniel, M., Rohrer, D., \& Bjork, R. (2008). Learning styles: Concepts and evidence. Psychological Science in the Public Interest, 9, 105-119.

Renkl, A. (2014). Toward an instructionally oriented theory of example-based learning. Cognitive Science, 38, 1-37.

Reisenzein, R. (2014). The attributional approach to emotion and motivation: Introduction to a special section of Emotion Review. Emotion Review, 6, 332-335.

Roediger, H. L. III, \& Pyc, M. A. (2012). Inexpensive techniques to improve education: Applying cognitive psychology to enhance educational practice. Journal of Applied Research in Memory and Cognition, 1, 242-248.

Roth, K. J., Garnier, H. E., Chen, C., Lemmens, M., Schwille, K., \& Wickler, N. I. (2011). Videobased lesson analysis: Effective science PD for teacher and student learning. Journal of Research in Science Teaching, 48, 117-148. 
Santagata, R., \& Yeh, C. (2014). Learning to teach mathematics and to analyze teaching effectiveness: Evidence from a video- and practice-based approach. Journal of Mathematics Teacher Education, 17, 491-514.

Schöll, E., \& Dutke, S. (2018). Metakognition in Lernprozessen als Facette von Heterogenität [Metacognition in learning as a facet of heterogeneity]. In D. Rott, N. Zeuch, C. Fischer, E. Souvignier, \& E. Terhart (Eds.). Dealing with Diversity. Innovative Lehrkonzepte in der Lehrer*innenbildung zum Umgang mit Heterogenität und Inklusion [Dealing with diversity. Innovative concepts in teacher education for dealing with diversity and inclusion] (pp. 175-187). Münster, Germany: Waxmann.

Schön, D. A. (1983). The reflective practitioner: How professionals think in action. New York: Basic Books. Schönpflug, W. (2004). Geschichte und Systematik der Psychologie [History and systematics of psychology]. Weinheim: Psychologie Verlags Union.

Schwartz, B. M., \& Gurung, R. A. R. (2012). Evidenced-based teaching for higher education. Washington, DC: American Psychological Association.

Seidel, T., \& Stürmer, K. (2014). Modeling and measuring the structure of professional vision in preservice teachers. American Educational Research Journal, 51, 739-771.

Sherin, M. G. (2007). The development of teachers' professional vision in video clubs. In R. Goldman, R. Pea, B. Barron, \& S. J. Denny (Eds.), Video research in the learning sciences (pp. 383-395). Mahwah, NJ: Erlbaum.

Thorndike, E. L. (1913). Educational psychology. Vol. 2: The psychology of learning. New York: Columbia University Press.

Westfälische Wilhelms-Universität (2017). Statistisches Jahrbuch 2016 [Statistical Yearbook 2016]. Retrieved under: https://www.uni-muenster.de

Wiggins, S., Chiriac, E. H., Abbad, G. L., Pauli, R., \& Worrell, M. (2016). Ask not only 'What can problem-based learning do for psychology?' But 'What can psychology do for problem-based learning?' A review of the relevance of problem-based learning for psychology teaching and research. Psychology Learning and Teaching, 15, 136-154.

Stephan Dutke

University of Muenster, Institute for Psychology in Education

stephan.dutke@uni-muenster.de

Manfred Holodynski

University of Muenster, Institute for Psychology in Education manfred.holodynski@uni-muenster.de

Elmar Souvignier

University of Muenster, Institute for Psychology in Education

elmar.souvignier@uni-muenster.de 